\title{
Placental Restriction Increases Adipose Leptin Gene Expression and Plasma Leptin and Alters Their Relationship to Feeding Activity in the Young Lamb
}

\author{
MILES J. DE BLASIO, DOMINIQUE BLACHE, KATHRYN L. GATFORD, JEFFREY S. ROBINSON, AND JULIE A. OWENS
}

Robinson Institute \& School of Paediatrics and Reproductive Health [M.J.D., K.L.G., J.S.R., J.A.O.], University of Adelaide, Adelaide, South Australia 5005, Australia; School of Animal Biology [D.B.], Faculty of Natural and Agricultural Sciences, University of Western Australia, Perth, Western Australia 6000, Australia

\begin{abstract}
Low birth weight and catch-up growth predict increased adiposity in children and adults. This may be due in part to leptin resistance, as adults who were born small exhibit increased plasma leptin concentration relative to adiposity. Placental restriction (PR), a major cause of intrauterine growth restriction, reduces size at birth and increases feeding activity and adiposity by $6 \mathrm{wk}$ in sheep. We hypothesized that PR would increase plasma leptin concentration and alter its relationship with feeding activity and adiposity in young lambs. Body size, plasma leptin, feeding activity, adiposity, leptin, and leptin receptor gene expression in adipose tissue were measured (12 control, 12 PR). PR reduced size at birth and increased adiposity. Plasma leptin concentration decreased with age, but to a lesser extent after PR and correlated positively with adiposity similarly in control and PR. PR increased plasma leptin concentration and perirenal adipose tissue leptin expression. Feeding activity correlated negatively with plasma leptin concentration in controls, but positively after PR. PR increases adipose tissue leptin expression and plasma leptin concentration, however, this increased abundance of peripheral leptin does not inhibit feeding activity (suckling event frequency), suggesting PR programs resistance to appetite and energy balance regulation by leptin, leading to early onset obesity. (Pediatr Res 67: $603-608,2010$ )
\end{abstract}

$\mathrm{R}$ estriction of substrate supply and growth in utero, evident as low birth weight and its associated accelerated infant growth, each predict obesity in children and adults $(1,2)$. Leptin is a peptide hormone secreted primarily by adipocytes that regulates energy intake, storage, and expenditure (3). Plasma leptin concentration correlates with body mass index and body fat mass in newborn infants and adults $(4,5)$ and acts at the hypothalamus to signal satiety and reduce the sensation of hunger. Leptin also increases thermogenesis and energy expenditure (6) and has other peripheral actions. Infants born small for gestational age undergo catch-up growth in the first few months of life and have greater body fat mass and higher circulating leptin concentrations as adults, than those of normal birth weight (7). Furthermore, for any given level of obesity in adult humans, plasma leptin concentration increases

Received September 1, 2009; accepted February 17, 2010

Correspondence: Miles J. De Blasio, Ph.D., Robinson Institute \& School of Paediatrics and Reproductive Health, University of Adelaide, Adelaide, South Australia 5005, Australia; e-mail: miles.deblasio@adelaide.edu.au

Supported by the National Health and Medical Research Council (NH\&MRC) Australia.

Each author has no commercial associations that might pose a conflict of interest in connection with the submitted article. with decreasing birth weight (7). Altered regulation of food intake by leptin may therefore contribute to perinatal programming of obesity by prenatal restriction $(8-10)$.

Consistent with this, maternal feed restriction in the rat advances the neonatal leptin surge from around 16 to $10 \mathrm{~d}$ and increases appetite, despite increased plasma leptin concentrations, and exacerbates high fat diet-induced obesity, with signs of central leptin resistance in offspring $(11,12)$. In contrast, in the sheep, which is more mature at birth than rodents, low birth weight due to maternal feed restriction or spontaneous variation in litter size does not alter plasma leptin in the fetus, neonate, or later in postnatal life, despite increased appetite and fatness in lambs who were small at birth (13-16).

A major cause of low birth weight and IUGR in humans and other species is placental insufficiency, which restricts delivery of oxygen and nutrients to the fetus (17). We have shown that placental restriction (PR) in the sheep induces hyperphagia in offspring after birth, during their catch-up growth, and increases central adiposity by $6 \mathrm{wk}(18)$. We therefore hypothesized that PR would increase adipose leptin expression, plasma leptin concentrations in absolute terms, and relative to fat mass, and that feeding activity would be inversely related to plasma leptin concentrations in control but not PR sheep.

\section{METHODS}

Animals and surgery. All procedures were approved by the University of Adelaide Animal Ethics Committee. The animals used in this study are a subset of a previously described cohort in which feeding activity was assessed (18). PR was induced by the removal of endometrial implantation sites (caruncles) from the uterus of the ewe before mating. The removal of endometrial caruncles restricts blood flow and the delivery of oxygen and nutrients to the fetus and hence restricts fetal growth $(19,20)$. PR reduces birth weight by $\sim 25 \%$ and is followed by neonatal catch-up growth and perturbed endocrine function $(18,21,22)$. Ewes were housed in individual pens and fed lucerne chaff twice daily ad libitum, with water ad libitum. Control ewes delivered 12 singleton lambs $(6 \mathrm{M}, 6 \mathrm{~F})$ and $\mathrm{PR}$ ewes delivered 12 singleton lambs (7M, 5F). Lambs were housed with the ewe, consumed milk and had access to the ewe's ration of lucerne chaff from birth. Catheters were inserted into the femoral artery and vein of the lamb under general anesthesia, induced and maintained by Halothane inhalation anesthetic (d5), as previously described (21). Fed blood samples were collected on d5, 10, 15 (before fasting for the feeding activity experiment), 20, 25, 35, and 40, and fasted samples were collected on $\mathrm{d} 8,15$ and 30 (after a $1 \mathrm{~h}$ fast).

Abbreviations: PR, placental restriction; CRL, crown-rump length; AGR, absolute growth rate; FGR, fractional growth rate 
Measurement of growth. At birth (d0) and at $5 \mathrm{~d}$ intervals up to d40 and at postmortem, weight, and crown-rump length (CRL) were measured. Body mass index was calculated as weight/CRL ${ }^{2}\left(\mathrm{~kg} / \mathrm{cm}^{2}\right)$, whereas ponderal index (PI) was calculated as weight/CRL ${ }^{3}\left(\mathrm{~kg} / \mathrm{cm}^{3}\right)$. Absolute growth rate (AGR) was calculated by linear regression as the slope of the relationship between age and each size parameter within an individual sheep. Fractional growth rate (FGR) was calculated as the AGR divided by the size of the parameter at birth.

Feeding activity. Feeding activity was characterized in lambs (12 controls, $12 \mathrm{PR})$ at $15 \pm 1 \mathrm{~d}$ as described previously (18). Briefly, lambs were fasted for $1 \mathrm{~h}$ (adjacent and visible to ewe), with water ad libitum, then returned to the ewe and observed for $1.5 \mathrm{~h}$ to measure the total number of suckling events (suckling event frequency, number of times the lamb attached to the udder and was observed to be swallowing per $1.5 \mathrm{~h}$ ) and the total suckling time (sum of lengths of suckling events during $1.5 \mathrm{~h}$ ). Feed and water were removed from the pen during the observation period so that only milk could be consumed by the lamb.

Analysis of plasma glucose, free fatty acids, insulin, and leptin. Fasting plasma glucose (Roche, Australia) and free fatty acids (FFA) (Wako Pure Industries, Japan) were measured on a Hitachi 912 automated analyzer. Fasting plasma insulin was measured by a double antibody, solid phase RIA (Abacus ALS). Plasma leptin was measured by ovine-specific leptin RIA using antibodies raised against bovine leptin (23). Intra and interassay coefficients of variation were $<5 \%$.

Postmortem. Lambs were killed at $43 \pm 2$ d by i.v. administration of sodium pentobarbitone (Virbac Australia Pty Ltd, NSW, Australia). Fat depots that could be accurately dissected (retroperitoneal, perirenal, and omental) were weighed, with visceral fat weight calculated as the sum of these depots.

RNA extraction and RT-PCR analysis of adipose tissue leptin expression. Total RNA was isolated from $100 \mathrm{mg}$ of frozen perirenal fat, using Trizol (Invitrogen, Australia). DNase treatment of RNA and quantitative real time PCR was performed as previously described $(24,25)$. Forward and reverse primer sequences, amplicon size, and GenBank ID for leptin, leptin receptor, and $\beta$-actin (housekeeper) were leptin (5'-ccaaaacctcatcaagacaatt-3', 5'-gtggagcccagggatgaagt-3', 109, NM_173928), leptin receptor (all forms) (5'-aaacaggtgcaaactggaacatac-3', 5'-taacacgtcaagcagaacatataaaaga-3', 132, NM_001012285.2) and Ovine $\beta$-actin (5'-atgtaccctggcatcgca-3', 5'-atccacatctgctggaaggtgg-3', 157, U39357). Data were analyzed using Rotor-Gene software v1.7 and the standard curve method of quantitation. Expression of leptin and leptin receptor was normalized against $\beta$-actin, which was unaltered by PR.

Statistical analysis. For single measures of each lamb (size at birth, growth rate, body composition, glucose, FFA, and insulin), effects of PR and sex were analyzed by ANOVA (SPSS v15). The effects of PR, sex, and age on plasma leptin were assessed by repeated measures ANOVA (SPSS v15). Because of the interaction between age and PR in the initial analysis, we then analyzed effects of PR on fed plasma leptin concentrations separately at each age (ANOVA). Only significant effects $(p<0.05)$ are reported throughout the results section. Associations between parameters were assessed by Pearson correlation or multiple linear regression analysis (SPSS v15).

\section{RESULTS}

Effects of PR on size at birth, postnatal growth, and adiposity. PR did not alter gestational age at delivery (Control: $150.7 \pm 1.8 \mathrm{~d}$; PR: $151.2 \pm 2.1 \mathrm{~d}, p=0.87)$. PR reduced weight $(p<0.05)$, but not CRL at birth (Table 1). PR increased FGR in terms of weight $(p<0.05$, Table 1$)$. Females were smaller than males at birth, and males grew faster after birth in absolute terms $(p<0.05$, Table 1). PR did not alter weight, CRL, or body mass index at $\mathrm{d} 43$, but females remained lighter than males (Table 1). PR lambs were fatter in terms of perirenal, retroperitoneal, and visceral fat as a percentage of body weight compared with controls (Table 1). Visceral fat as a percentage of body weight correlated negatively with birth weight in PR females only $(r=-0.95, n=$ $5, p=0.007)$.

Effects of PR on plasma glucose, insulin, and FFA. PR did not alter fasting plasma glucose, FFA, or leptin concentrations (d15). At d30, PR increased plasma glucose (control: $5.86 \pm 0.27 \mathrm{mM}$; PR: $6.78 \pm 0.29 \mathrm{mM}, p=0.004)$, and altered plasma insulin differently in males and females (control males: $15.8 \pm 3.8 \mathrm{ng} / \mathrm{mL}$; PR males: $18.7 \pm 4.0 \mathrm{ng} / \mathrm{mL}$; control females: $8.2 \pm 4.8 \mathrm{ng} / \mathrm{mL}$; PR females: $33.0 \pm 6.2$ ng/mL; PR: $p=0.009$; sex: $p=0.048$; PR*sex: $p=0.033$, such that PR increased plasma insulin in females $(p=0.031)$ but not in males $(p=0.12)$.

Effects of PR on plasma leptin concentration. Plasma leptin concentrations in fed lambs decreased with age until d20 (repeated measures, age; $p=0.014$, Fig. 1) and changed differently with age in PR compared with controls [repeated

Table 1. Effect of PR on size at birth, postnatal growth rate, and post-mortem size in sheep

\begin{tabular}{|c|c|c|c|c|c|c|c|}
\hline & \multicolumn{2}{|c|}{ Male } & \multicolumn{2}{|c|}{ Female } & \multicolumn{3}{|c|}{$p$ value (ANOVA) } \\
\hline & Control (6) & $\operatorname{PR}(7)$ & Control (6) & PR (5) & PR & $\mathrm{S}$ & $\mathrm{PR} \times \mathrm{S}$ \\
\hline \multicolumn{8}{|l|}{ Birth phenotype } \\
\hline Weight (kg) & $5.71 \pm 0.46$ & $4.72 \pm 0.43$ & $4.60 \pm 0.43$ & $3.50 \pm 0.47$ & 0.037 & 0.020 & NS \\
\hline Crown-rump length $(\mathrm{cm})$ & $53.6 \pm 1.7$ & $51.1 \pm 1.6$ & $50.6 \pm 1.7$ & $47.0 \pm 1.8$ & NS & 0.050 & NS \\
\hline Body mass index $\left(\mathrm{kg} / \mathrm{m}^{2}\right)$ & $19.8 \pm 1.1$ & $18.1 \pm 1.0$ & $17.4 \pm 1.0$ & $15.9 \pm 1.1$ & NS & 0.047 & NS \\
\hline \multicolumn{8}{|l|}{ Postnatal growth } \\
\hline Weight (kg/d) & $0.36 \pm 0.02$ & $0.34 \pm 0.02$ & $0.28 \pm 0.02$ & $0.28 \pm 0.02$ & NS & 0.002 & NS \\
\hline Weight $(\% / \mathrm{d})$ & $6.8 \pm 0.5$ & $7.5 \pm 0.5$ & $6.8 \pm 0.5$ & $8.5 \pm 0.5$ & 0.042 & NS & NS \\
\hline \multicolumn{8}{|l|}{ Postmortem size (d43) } \\
\hline Weight (kg) & $20.1 \pm 0.8$ & $19.2 \pm 0.9$ & $16.2 \pm 1.0$ & $15.6 \pm 1.1$ & NS & 0.001 & NS \\
\hline Crown-rump length $(\mathrm{cm})$ & $79.6 \pm 2.4$ & $79.7 \pm 2.4$ & $77.9 \pm 2.8$ & $80.7 \pm 3.4$ & NS & NS & NS \\
\hline Body mass index $\left(\mathrm{kg} / \mathrm{m}^{2}\right)$ & $30.5 \pm 1.2$ & $28.0 \pm 1.2$ & $27.9 \pm 1.4$ & $27.2 \pm 1.7$ & NS & NS & NS \\
\hline \multicolumn{8}{|l|}{ Postmortem fat depots (d43) } \\
\hline Perirenal fat $(\mathrm{g})$ & $109.6 \pm 8.3$ & $140.4 \pm 9.6$ & $114.3 \pm 12.1$ & $127.6 \pm 12.2$ & NS & NS & NS \\
\hline Perirenal fat (\% body weight) & $84.6 \pm 7.3$ & $127.9 \pm 7.8$ & $141.2 \pm 9.5$ & $163.4 \pm 9.9$ & 0.029 & 0.034 & NS \\
\hline Retroperitoneal fat (g) & $76.5 \pm 7.4$ & $98.2 \pm 8.8$ & $84.4 \pm 11.0$ & $103.4 \pm 11.1$ & NS & NS & NS \\
\hline Retroperitoneal fat ( $\%$ body weight) & $58.4 \pm 7.4$ & $89.1 \pm 7.6$ & $103.8 \pm 9.7$ & $129.3 \pm 10.2$ & 0.049 & 0.026 & NS \\
\hline Omental fat (g) & $169.7 \pm 12.2$ & $177.9 \pm 13.1$ & $144.1 \pm 14.1$ & $144.1 \pm 17.5$ & NS & NS & NS \\
\hline Omental fat ( $\%$ body weight) & $136.2 \pm 9.7$ & $157.2 \pm 9.8$ & $179.5 \pm 11.1$ & $194.4 \pm 13.9$ & NS & NS & NS \\
\hline Visceral fat $(\mathrm{g})$ & $356.3 \pm 26.1$ & $416.6 \pm 29.7$ & $348.1 \pm 35.2$ & $354.6 \pm 36.1$ & NS & NS & NS \\
\hline Visceral fat ( $\%$ body weight) & $284.6 \pm 21.5$ & $373.8 \pm 21.6$ & $428.7 \pm 26.4$ & $471.6 \pm 31.2$ & 0.046 & 0.023 & NS \\
\hline
\end{tabular}

Values expressed as means \pm SEM and number of animals within parentheses.

$\mathrm{PR}$, placentally restricted; $\mathrm{S}$, sex; NS, not significant. 


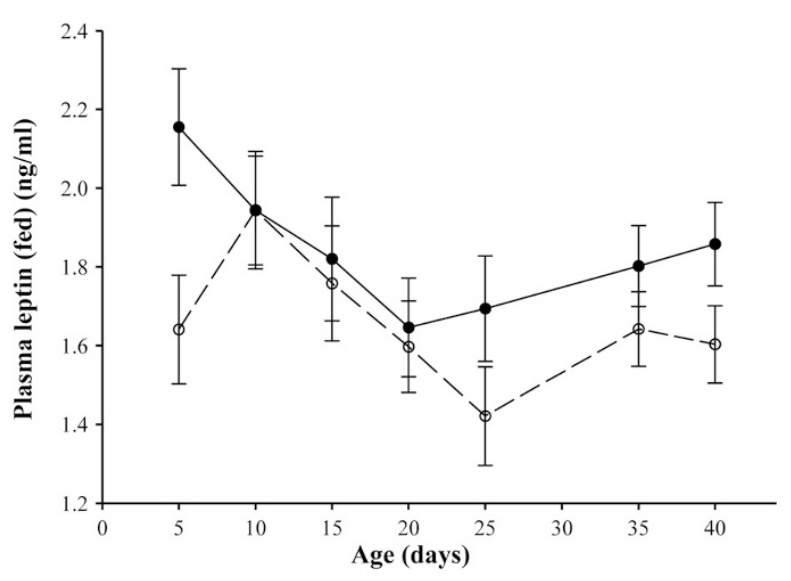

Figure 1. PR increases plasma leptin in young lambs. Fed plasma leptin concentrations (controls: $n=12$; PR: $n=12$ ) were analyzed by repeated measures ANOVA for effects of treatment and time. Plasma leptin concentrations were reduced with age $(p=0.014)$ and in a cubic fashion with treatment $(p=0.001)$. Values are mean \pm SEM. Control $(\bigcirc)$, PR $(\bullet)$.
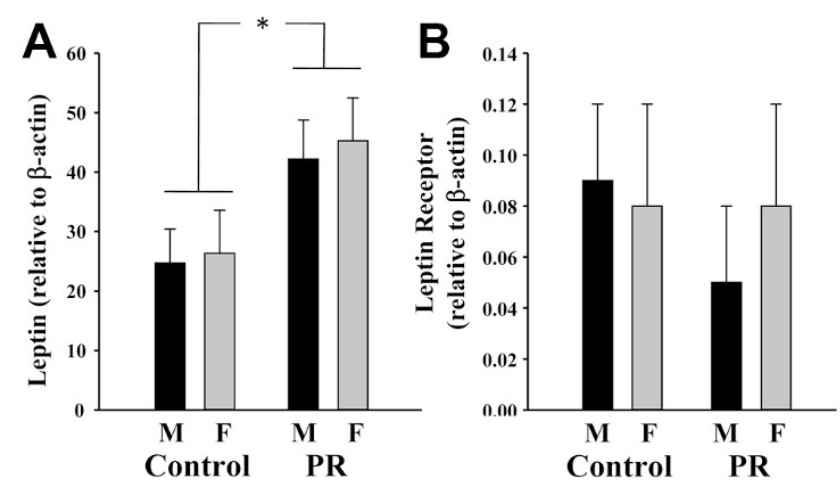

Figure 2. PR increases expression of leptin but not leptin receptor in perirenal fat at postmortem (d43). Perirenal fat leptin expression was increased at postmortem in PR lambs $(p=0.013)$. Values are mean \pm SEM.

measures, age*PR; $p=0.001$ (cubic), Fig. 1]. PR increased fed plasma leptin concentrations at d5 (Control: $1.58 \pm 0.17$ ng/mL; PR: $2.18 \pm 0.15 \mathrm{ng} / \mathrm{mL}, p=0.008$ ) and $\mathrm{d} 40$ (Control: $1.54 \pm 0.14 \mathrm{ng} / \mathrm{mL}$; PR: $1.88 \pm 0.13 \mathrm{ng} / \mathrm{mL}, p=0.046)$. PR also increased fed plasma leptin concentrations regardless of age $(p=0.049)$. Fasted plasma leptin concentrations were not altered by PR or sex, and fed and fasted plasma leptin concentrations did not differ between males and females from d5 to d40 (data not shown). Fasting plasma leptin concentrations were lower at $\mathrm{d} 30(1.55 \pm 0.11 \mathrm{ng} / \mathrm{mL})$ compared with $\mathrm{d} 8(1.89 \pm 0.13 \mathrm{ng} / \mathrm{mL})(p=0.005)$. Plasma leptin concentrations (d5-30) and average fed and fasted plasma leptin concentrations each correlated negatively with birth weight in PR female lambs only ( $r=0.78$ to $0.92, n=5, p<0.05$ ).

Relationships among plasma leptin concentration, insulin, perirenal leptin, and leptin receptor gene expression and fat mass. PR increased perirenal expression of leptin $(p=0.013$, Fig. 2A), but not leptin receptor (Fig. 2B), in perirenal fat (d43). Perirenal adipose expression of leptin and leptin receptor did not differ between males and females (Fig. $2 A$ and $B$ ). Fed plasma leptin concentrations (d40) correlated positively with perirenal expression of leptin in control and PR lambs (control: $r=0.73$, $n=8, p=0.02$; PR: $\mathrm{r}=0.54, n=11, p=0.043)$. Fed plasma leptin concentrations (d40) correlated positively with perirenal expression of leptin receptor in PR lambs only (control: NS; PR: $r=0.63, n=11, p=0.019$ ).

Perirenal expression of leptin and leptin receptor did not correlate with perirenal fat mass, but perirenal expression of leptin correlated positively with visceral fat mass in control lambs (control: $r=0.54, n=12, p=0.036$; PR: $r=0.17$, $n=10$, NS; Fig. $3 A$ ) and with visceral fat mass as a percentage of body weight in PR lambs (control: $r=0.42, n=12$, NS: PR: $r=0.55, n=10, p=0.048$; Fig. $3 B$ ). Perirenal leptin receptor expression correlated positively with visceral fat mass (control: $r=0.04, n=12$, NS; PR: $r=0.59, n=$ $10, p=0.044$; Fig. $3 D$ ) and with visceral fat as a percentage of body weight (control: $r=0.14, n=12$, NS; PR: $r=0.73$, $n=10, p=0.008$; Fig. $3 E$ ) in PR lambs only.

Fasting plasma insulin concentration (d30) correlated positively with perirenal leptin expression in PR lambs (control: $r=0.32, n=10$, NS; PR: $r=0.66, n=7, p=0.037$, Fig. $3 C$ ) and leptin receptor expression in control lambs (control: $r=0.91, n=11, p<0.001$; PR: $r=0.60, n=7, p<0.1$, Fig. $3 F)$.

Plasma leptin concentration (d40) correlated positively with total visceral fat mass (control: $r=0.63, n=8, p=0.025$; PR: $r=0.67, n=10, p=0.017$, Fig. $4 A$ ) and total visceral fat mass as a percentage of body weight (control: $r=0.69$, $n=8, p=0.029$; PR: $r=0.60, n=10, p=0.034$, Fig. $4 B$ ) in males and females combined.

Postnatal growth and plasma leptin concentration. Plasma leptin concentration (d5-15, d25-40) correlated positively with FGR of CRL ( $r=0.55$ to $0.71, p<0.05)$, and AGR and FGR of abdominal circumference $(r=0.50$ to $0.73, p<0.05)$ in controls. Mean fed and fasted plasma leptin concentration correlated positively with AGR and FGR of CRL and abdominal circumference (fed: $r=0.53$ and 0.57; fasted: $r=0.50$ and 0.63 , respectively; $p<0.05$ ) in controls, and with FGR weight (fed: $r=0.59$; fasted: $r=0.50 ; p<0.05$ ) in PR lambs. Plasma leptin concentrations (d5-30) correlated positively with FGR weight $(\mathrm{r}=0.47$ to $0.66, p<0.05)$ in PR lambs. Plasma leptin concentration (d10-20) correlated positively with FGR abdominal and thoracic circumferences ( $r=$ 0.61 to $0.66, p<0.05$ ) in PR lambs.

Relationships between feeding activity and plasma leptin concentration. The total number of suckling events (number per $1.5 \mathrm{~h}$ observation period, d15), correlated negatively with plasma leptin concentration (d15) in control lambs, but positively in PR lambs (control: $r=-0.52, n=12, p=0.038$; PR: $r=0.56, n=11, p=0.044$, Fig. 5). Total suckling time (d15) correlated positively with plasma leptin concentrations in PR lambs, but not controls, at d5 (control: $r=-0.23, n=$ 12, NS; PR: $r=0.49, n=11, p<0.05$ ), d8 (control: $r=$ $-0.12, n=12$, NS; PR: $r=0.56, n=11, p<0.05)$, and $\mathrm{d} 25$ (control: $r=-0.26, n=12$, NS; PR: $r=0.52, n=11, p<$ 0.05). The total number of suckling events corrected for body weight correlated negatively with plasma leptin concentration (d15) in control lambs, but positively in PR lambs (control: $r=-0.56, n=12, p<0.05$; PR: $r=0.54, n=11, p<$ $0.05)$. Total suckling time (d15) corrected for body weight did 


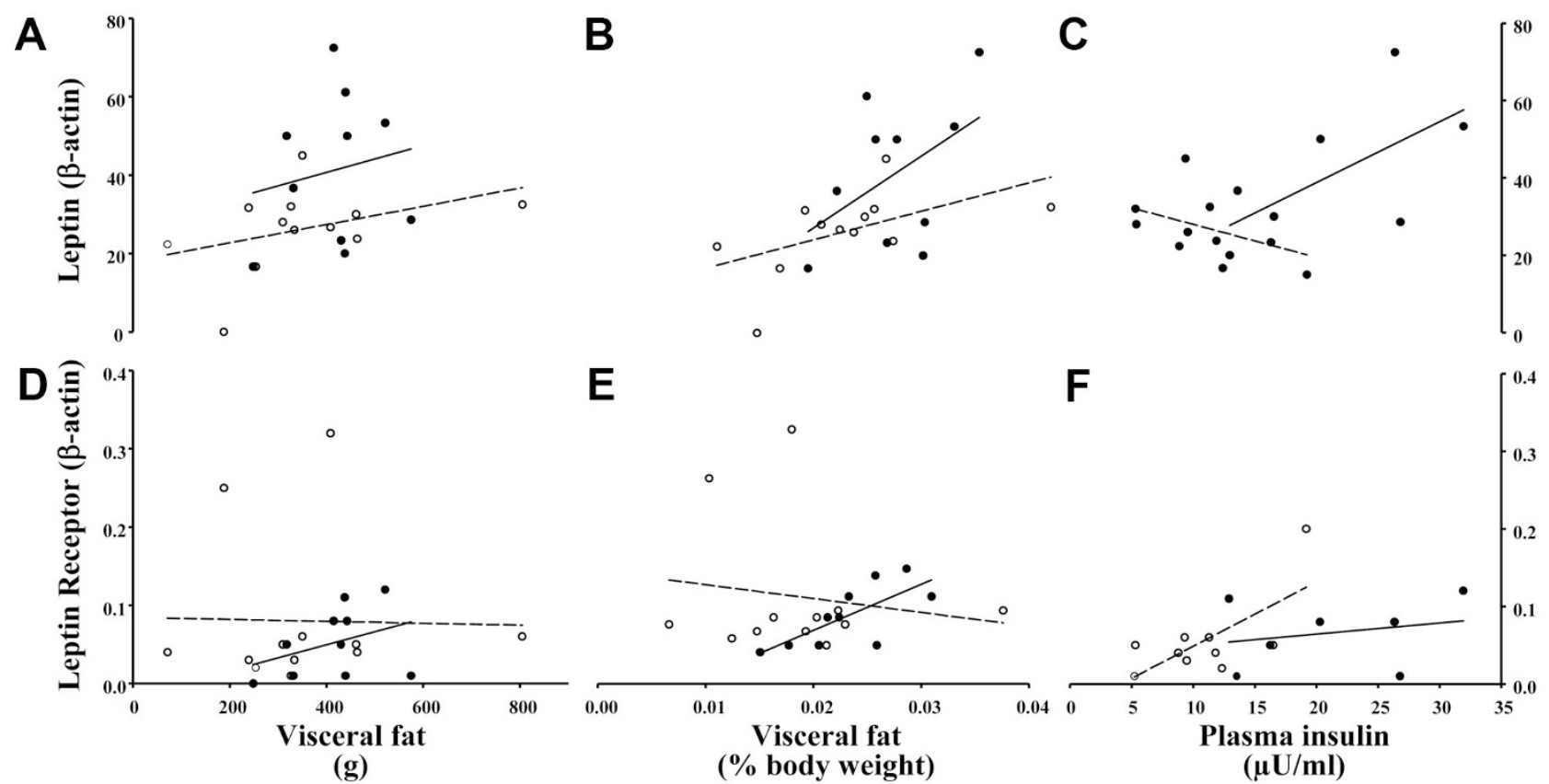

Figure 3. PR alters relationships between visceral fat mass and plasma insulin and leptin and leptin receptor gene expression in young lambs. Leptin gene expression correlated positively with $(A)$ visceral fat in controls (control: $r=0.54, n=12, p=0.036$; PR: $r=0.17, n=10$, NS), and (B) visceral fat as a percentage of body weight in PR lambs (control: $r=0.42, n=12$, NS: PR: $r=0.55, n=10, p=0.048$ ). Leptin receptor gene expression correlated positively with $(D)$ visceral fat in PR lambs (control: $r=0.04, n=12$, NS; PR: $r=0.59, n=10, p=0.044$ ) and $(E)$ visceral fat as a percentage of body weight in PR lambs (control: $r=0.14, n=12$, NS; PR: $r=0.73, n=10, p=0.008$ ). Fasting plasma insulin concentrations correlated positively with $(C)$ leptin expression in PR lambs (control: $r=0.32, n=10$, NS; PR: $r=0.66, n=7, p=0.037$ ) and $(F)$ leptin receptor expression in control lambs (control: $r=0.91, n=10$, $p<0.001$; PR: $r=0.60, n=7, p<0.1)$. Control (O), PR (๑).
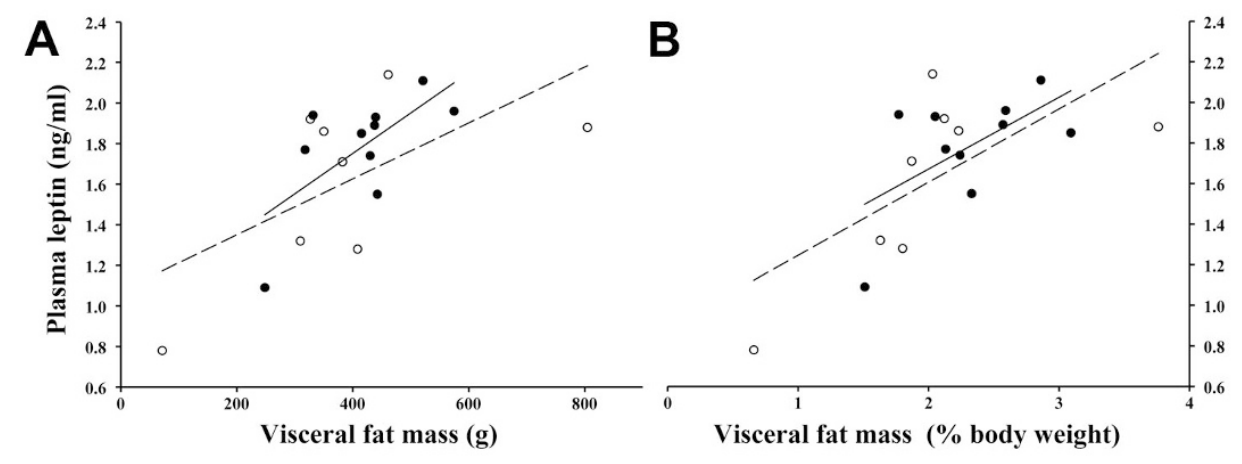

Figure 4. Plasma leptin concentration correlates positively with visceral fat mass in young lambs. Fed plasma leptin concentrations (d40) correlated positively with $(A)$ total visceral fat mass (control: $r=0.63, n=$ $8, p=0.025$; PR: $r=0.67, n=10, p=$ $0.017)$ and $(B)$ total visceral fat mass as a percentage of body weight (control: $r=$ 0.69, $n=8, p=0.029$; PR: $r=0.60, n=$ $10, p=0.034)$. Control (O), PR (O)

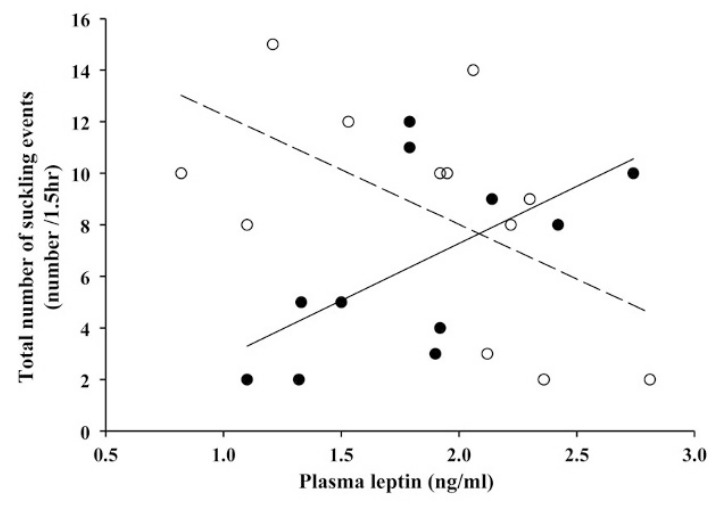

Figure 5. PR reverses the relationship between appetite and plasma leptin concentration in young lambs. Fasting plasma leptin (d15) correlated negatively with the number of suckling events in control $(r=-0.52, n=12, p=$ $0.038)$ but positively in PR $(r=0.56, n=11, p=0.044)$ lambs. Control $(\bigcirc)$, PR (O). not correlate with plasma leptin concentrations in control or PR lambs (control: $r=0.22, n=12$, NS; PR: $r=0.07, n=$ $11, \mathrm{NS})$.

\section{DISCUSSION}

We have shown for the first time that PR increases perirenal expression and circulating leptin in the first month of life in the young lamb. Increased plasma leptin concentration in the young PR lamb is consistent with similar observations in human infants aged $1 \mathrm{y}$ following IUGR (26). We also report for the first time that in the normal lamb, feeding activity, measured as suckling event frequency, is negatively related to plasma leptin concentration at $2 \mathrm{wk}$, suggesting that the role of leptin in central regulation of appetite and satiety is established by this age in the sheep. Crucially, PR abolishes this inverse relationship of plasma leptin concentration with feeding activity, in terms of the number and total duration of 


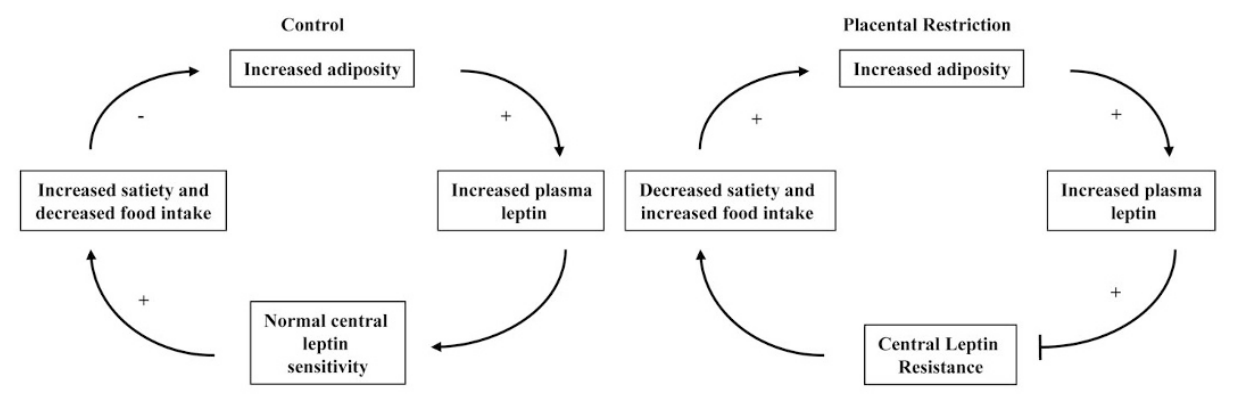

Figure 6. PR alters the relationship of plasma leptin concentration to feeding activity in the young lamb. We propose that PR causes central leptin resistance which disregulates satiety or appetite, thereby increasing appetite and food intake, resulting in continued expansion of adipose tissue and further increases in leptin, in contrast to the control lamb with intact central negative feedback of appetite by leptin.

feeding events, suggesting that restriction of growth before birth may impair central leptin action after birth, contributing to their hyperphagia (Fig. 6).

We have shown that plasma leptin concentration in the young lamb decreases after birth until d20 then plateaus. This is consistent with previous studies in lambs where plasma leptin concentration increased from birth to d5 and then declined to d47 (27), while in humans, plasma leptin concentration decreases in boys from 6 to 20 y (28). Plasma leptin concentration correlated with total and relative visceral fat mass in lambs at $6 \mathrm{wk}$, suggesting that higher leptin in PR lambs in part reflects their greater fat mass. Given that PR lambs have reduced absolute perirenal fat mass in late gestation (29), their elevated leptin at d5 is, however, unlikely to reflect increased fat mass. In humans, plasma leptin concentration also correlates positively with circulating levels of insulin independent of body fat mass, in lean and obese children, and in adults remains increased several days after insulin infusion, and may be a predictor of insulin resistance (30-33). In this study, plasma leptin concentration similarly correlated with fasting plasma insulin concentration. We have previously observed that PR enhances insulin suppression of circulating FFA in young lambs postnatally (21), suggesting increased insulin sensitivity of adipose tissue, and increased insulin action on adipocytes may therefore also contribute to increased circulating leptin after PR. These findings suggest that PR alters plasma leptin concentration in part by programming of altered insulin action and body composition $(9,12,34)$.

Leptin has been proposed to act as a growth promoter in early life (26). Here, we show that plasma leptin concentration predicted accelerated growth in terms of CRL and abdominal circumference in controls, whereas in PR lambs plasma leptin concentration was predictive of catch-up growth of soft tissues, evident as increased FGR of weight and abdominal circumference. IUGR also increases fat deposition in human infants $(1,2)$, whose plasma leptin concentration increases above that of normal birth weight infants during the first year of life (26). These findings may however reflect common underlying drivers of both growth and plasma leptin concentration following IUGR rather than altered leptin action on growth.

In this study, we have established that plasma leptin concentration and suckling event frequency after fasting are inversely related in the normal lamb at $2 \mathrm{wk}$. Elements of the appetite and feeding regulatory networks in the brain are present before birth in the sheep, nonhuman primate and the human fetus (35-37). In the nonhuman primate and the sheep, structural development of the appetite regulatory network occurs during the third trimester of pregnancy $(37,38)$. Our findings suggest that increased circulating leptin decreases appetite, at least measured by suckling event frequency, implying that these pathways are functional by $2 \mathrm{wk}$ in the sheep. In the rat, central pathways of appetite regulation develop from d14.5 gestation, but are not functional until $2 \mathrm{wk}$ after birth, suggesting that although the rat is atricial, onset of regulation of feed intake occurs at least by the same time as the precocial sheep $(35,39)$. Previously, we reported that PR lambs have increased feeding activity in terms of increased suckling time (18). We now have evidence that PR abolishes, and indeed reverses, the association of plasma leptin concentration and suckling time and number of suckling events in the 2-wk-old lamb. Furthermore, the PR lamb becomes hyperinsulinaemic by this age $(18,21)$. Normally, increased plasma leptin and insulin concentrations act to suppress appetite (40), but we have shown that plasma insulin and plasma leptin are increased in PR lambs in conjunction with increased feeding activity, suggesting PR may alter central sensitivity to these hormones and/or the activity of other appetite-regulating hormones. Contributions of milk yield and composition to altered feeding behavior in the PR lamb cannot, however, be excluded in this study. In the rat, bilateral uterine artery ligation in late pregnancy decreases milk intake of pups in early postnatal life, measured by the weigh-suckle-weigh technique, although milk calcium and protein contents are not altered (41). Further studies are required to differentiate effects of PR on milk yield (supply) and appetite (demand). Suckling event frequency and total suckling time correlated positively with relative growth rates in these lambs (18), however, suggesting that these do reflect nutrient intake. In the present cohort, we investigated responses to endogenous leptin and insulin only, and studies of food intake, appetite, and energy balance responses to chronic infusions of leptin and/or insulin are needed to provide direct evidence for central resistance. It has been suggested that leptin promotes the formation of neural projections from the arcuate nucleus to the hypothalamus which may control food intake and adiposity later in life, and defects in these projections may reduce leptin signaling (9). In rats, leptin deficiency in early life, particularly during the postnatal surge in leptin, can modify the numbers of these projections and are implicated in onset of later leptin resistance $(8,42)$. Certainly, the PR fetal sheep exhibits leptin deficiency in late 
gestation in terms of reduced adipose tissue leptin expression, although plasma leptin concentration is unaltered (29). Here we saw no evidence for leptin deficiency in PR lambs at d5 (Fig. 1), but did not examine earlier ages. Thus, key questions for the future are how PR modifies circulating leptin before and after birth, and whether leptin resistance and increased adiposity apparent in PR lambs by $6 \mathrm{wk}$ might in part reflect abnormal neuronal organization or decreased hypothalamic leptin receptor expression, resulting in diminished responsiveness of these neurons to leptin and contributing to increased feeding activity and adiposity postnatally.

We conclude that PR increases plasma leptin concentration in young progeny and is associated with catch-up growth of soft tissues, increased feeding activity and central obesity. Importantly, we have shown for the first time that plasma leptin predicts reduced feeding activity (measured as suckling event frequency) after fasting in the young control lamb and that this is reversed by PR. This is consistent with placental programming of central leptin resistance, which may contribute to hyperphagia, onset of central obesity and later metabolic dysfunction which develop in the PR sheep postnatally $(18,21)$.

\section{REFERENCES}

1. Rogers I; EURO-BLCS Study Group 2003 The influence of birthweight and intrauterine environment on adiposity and fat distribution in later life. Int J Obes Relat Metab Disord 27:755-777

2. Ong KK, Ahmed ML, Emmett PM, Preece MA, Dunger DB 2000 Association between postnatal catch-up growth and obesity in childhood: prospective cohort study. BMJ 320:967-971

3. Friedman JM, Halaas JL 1998 Leptin and the regulation of body weight in mammals. Nature 395:763-770

4. Maffei M, Halaas J, Ravussin E, Pratley RE, Lee GH, Zhang Y, Fei H, Kim S, Lallone R, Ranganathan S, Kern PA, Friedman JM 1995 Leptin levels in human and rodent: measurement of plasma leptin and ob RNA in obese and weight-reduced subjects. Nat Med 1:1155-1161

5. Considine RV, Sinha MK, Heiman ML, Kriauciunas A, Stephens TW, Nyce MR, Ohannesian JP, Marco CC, McKee LJ, Bauer TL, Caro JF 1996 Serum immunoreactive-leptin concentrations in normal-weight and obese humans. N Engl J Med 334:292-295

6. Huang L, Li C 2000 Leptin: a multifunctional hormone. Cell Res 10:81-92

7. Phillips DI, Fall CH, Cooper C, Norman RJ, Robinson JS, Owens PC 1999 Size at birth and plasma leptin concentrations in adult life. Int J Obes Relat Metab Disord 23:1025-1029

8. Bouret SG, Gorski JN, Patterson CM, Chen S, Levin BE, Simerly RB 2008 Hypothalamic neural projections are permanently disrupted in diet-induced obese rats. Cell Metab 7:179-185

9. Bouret SG, Simerly RB 2006 Developmental programming of hypothalamic feeding circuits. Clin Genet 70:295-301

10. Cianfarani S, Germani D, Branca F 1999 Low birthweight and adult insulin resistance: the "catch-up growth" hypothesis. ch Dis Child Fetal Neonatal Ed 81:F71-F73

11. Yura S, Itoh H, Sagawa N, Yamamoto H, Masuzaki H, Nakao K, Kawamura M, Takemura M, Kakui K, Ogawa Y, Fujii S 2005 Role of premature leptin surge in obesity resulting from intrauterine undernutrition. Cell Metab 1:371-378

12. Vickers MH, Breier BH, Cutfield WS, Hofman PL, Gluckman PD 2000 Fetal origins of hyperphagia, obesity, and hypertension and postnatal amplification by hypercaloric nutrition. Am J Physiol Endocrinol Metab 279:E83-E87

13. Yuen BS, Owens PC, McFarlane JR, Symonds ME, Edwards LJ, Kauter KG, McMillen IC 2002 Circulating leptin concentrations are positively related to leptin messenger rna expression in the adipose tissue of fetal sheep in the pregnant ewe fed at or below maintenance energy requirements during late gestation. Biol Reprod 67:911-916

14. Husted SM, Nielsen MO, Tygesen MP, Kiani A, Blache D, Ingvartsen KL 2007 Programming of intermediate metabolism in young lambs affected by late gestational maternal undernourishment. Am J Physiol Endocrinol Metab 293:E548-E557

15. Greenwood PL, Hunt AS, Hermanson JW, Bell AW 1998 Effects of birth weight and postnatal nutrition on neonatal sheep: I. Body growth and composition, and some aspects of energetic efficiency. J Anim Sci 76:2354-2367
16. Ehrhardt RA, Greenwood PL, Bell AW, Boisclair YR 2003 Plasma leptin is regulated predominantly by nutrition in preruminant lambs. J Nutr 133:4196-4201 17. Pardi G, Marconi AM, Cetin I 2002 Placental-fetal interrelationship in IUGR fetuses-a review. Placenta 23:S136-S141

18. De Blasio MJ, Gatford KL, Robinson JS, Owens JA 2007 Placental restriction of fetal growth reduces size at birth and alters postnatal growth, feeding activity and adiposity in the young lamb. Am J Physiol Regul Integr Comp Physiol 292:R875R886

19. Robinson JS, Kingston EJ, Jones CT, Thornburn GD 1979 Studies on experimental growth retardation in sheep. The effect of removal of endometrial caruncles on fetal size and metabolism. J Dev Physiol 1:379-398

20. Owens JA, Falconer J, Robinson JS 1987 Effect of restriction of placental growth on oxygen delivery to and consumption by the pregnant uterus and fetus. J Dev Physiol 9:137-150

21. De Blasio MJ, Gatford KL, McMillen IC, Robinson JS, Owens JA 2007 Placental restriction of fetal growth increases insulin action, growth and adiposity in the young lamb. Endocrinology 148:1350-1358

22. De Blasio MJ, Gatford KL, Robinson JS, Owens JA 2006 Placental restriction alters circulating thyroid hormone in the young lamb postnatally. Am J Physiol Regul Integr Comp Physiol 291:R1016-R1024

23. Blache D, Tellam RL, Chagas LM, Blackberry MA, Vercoe PE, Martin GB 2000 Level of nutrition affects leptin concentrations in plasma and cerebrospinal fluid in sheep. J Endocrinol 165:625-637

24. Gatford KL, Mohammad SN, Harland ML, De Blasio MJ, Fowden AL, Robinson JS, Owens JA 2008 Impaired \{beta\}-cell function and inadequate compensatory increases in $\{$ beta\}-cell mass following intrauterine growth restriction in sheep. Endocrinology 149:5118-5127

25. Irving-Rodgers HF, Harland ML, Sullivan TR, Rodgers RJ 2009 Studies of granulosa cell maturation in dominant and subordinate bovine follicles: novel extracellular matrix focimatrix is co-ordinately regulated with cholesterol side-chain cleavage CYP11A1. Reproduction 137:825-834

26. Jaquet D, Leger J, Tabone MD, Czernichow P, Levy-Marchal C 1999 High serum leptin concentrations during catch-up growth of children born with intrauterine growth retardation. J Clin Endocrinol Metab 84:1949-1953

27. McFadin EL, Morrison CD, Buff PR, Whitley NC, Keisler DH 2002 Leptin concentrations in periparturient ewes and their subsequent offspring. J Anim Sci 80:738-743

28. Blum WF, Englaro P, Hanitsch S, Juul A, Hertel NT, Muller J, Skakkebak NE, Heiman ML, Birkett M, Attanasio AM, Kiess W, Rascher W 1997 Plasma leptin levels in healthy children and adolescents: dependence on body mass index, body fat mass, gender, pubertal stage, and testosterone. J Clin Endocrinol Metab 82:29042910

29. Duffield JA, Vuocolo T, Tellam R, Yuen BS, Muhlhausler BS, McMillen IC 2008 Placental restriction of fetal growth decreases IGF1 and leptin mRNA expression in the perirenal adipose tissue of late gestation fetal sheep. Am J Physiol Regul Integr Comp Physiol 294:R1413-R1419

30. Steinberger J, Steffen L, Jacobs DR Jr, Moran A, Hong C, Sinaiko AR 2003 Relation of Leptin to Insulin Resistance Syndrome in Children. Obes Res 11:1124-1130

31. Haffner SM, Miettinen H, Mykkanen L, Karhapaa P, Rainwater DL, Laakso M 1997 Leptin concentrations and insulin sensitivity in normoglycemic men. Int J Obes Relat Metab Disord 21:393-399

32. Boden G, Chen X, Kolaczynski JW, Polansky M 1997 Effects of Prolonged Hyperinsulinemia on Serum Leptin in Normal Human Subjects. J Clin Invest 100:1107-1113

33. Segal KR, Landt M, Klein S 1996 Relationship between insulin sensitivity and plasma leptin concentration in lean and obese men. Diabetes 45:988-991

34. McMillen IC, Edwards LJ, Duffield J, Muhlhausler BS 2006 Regulation of leptin synthesis and secretion before birth: implications for the early programming of adult obesity. Reproduction 131:415-427

35. Grove KL, Smith MS 2003 Ontogeny of the hypothalamic neuropeptide Y system. Physiol Behav 79:47-63

36. Koutcherov Y, Mai JK, Paxinos G 2003 Hypothalamus of the human fetus. J Chem Neuroanat 26:253-270

37. Warnes KE, Morris MJ, Symonds ME, Phillips ID, Clarke IJ, Owens JA, McMillen IC 1998 Effects of increasing gestation, cortisol and maternal undernutrition on hypothalamic neuropeptide $\mathrm{Y}$ expression in the sheep fetus. J Neuroendocrinol 10:51-57

38. Grayson BE, Allen SE, Billes SK, Williams SM, Smith MS, Grove KL 2006 Prenatal development of hypothalamic neuropeptide systems in the nonhuman primate. Neuroscience 143:975-986

39. Grove KL, Allen S, Grayson BE, Smith MS 2003 Postnatal development of the hypothalamic neuropeptide Y system. Neuroscience 116:393-406

40. Schwartz MW, Figlewicz DP, Baskin DG, Woods SC, Porte D Jr 1992 Insulin in the brain: a hormonal regulator of energy balance. Endocr Rev 13:387-414

41. O’Dowd R, Kent JC, Moseley JM, Wlodek ME 2008 Effects of uteroplacental insufficiency and reducing litter size on maternal mammary function and postnatal offspring growth. Am J Physiol Regul Integr Comp Physiol 294:R539-R548

42. Delahaye F, Breton C, Risold P, Enache M, Dutriez-Casteloot I, Laborie C, Lesage J, Vieau D 2008 Maternal Perinatal Undernutrition Drastically Reduces Postnatal Leptin Surge and Affects the Development of Arcuate Nucleus Proopiomelanocortin Neurons in Neonatal Male Rat Pups. Endocrinology 149:470-475 